\title{
SHARING WALL PROJECT SEBAGAI BENTUK UPAYA KONSERVASI SUMBERDAYA BATUBARA
}

\author{
Herri Lubis \\ Kepala Teknik Tambang PT Banjarsari Pribumi (Titan Global Energy - Coal)
}

\begin{abstract}
ABSTRAK
Salah satu bentuk usaha konservasi sumberdaya mineral dan batubara (seperti yang diamanatkan dalam PP No. 55 Tahun 2010) adalah pengelolaan dan atau pemanfaatan cadangan marginal. Contoh pemanfaatan cadangan marginal ini adalah dengan memaksimalkan penambangan cadangan batubara di perbatasan antara 2 (dua) atau beberapa konsesi yang saling bersinggungan. Cadangan batubara di perbatasan ini seringkali ditinggal karena beberapa pertimbangan dari pemegang konsesi. Dalam makalah ini menggunakan studi kasus pada penambangan bersama di Izin Usaha Pertambangan (IUP) PT Banjarsari Pribumi (PTBP) dan IUP PT Budi Gema Gempita (PTBGG) di Kabupatan Lahat, Sumatera Selatan. Kerjasama penambangan di perbatasan konsesi yang saling bersinggungan ini dinamakan dengan "Sharing Wall Project". Tujuan dari penulisan makalah ini adalah memberikan informasi dan panduan kepada para pemegang konsesi yang saling berimpitan dalam melakukan kerjasama penambangan sesuai dengan peraturan perundangan yang berlaku. Sampai saat ini "Sharing Wall Project" antara IUP PTBP dan PTBGG ini sudah menambang batubara sebesar 350,000 ton dari Sharing Wall Project ini untuk masing-masing konsesi. Dengan "Sharing Wall Project" ini berpotensi adanya penambahan cadangan marginal sebesar 1,000,000 ton yang bisa ditambang untuk masing-masing IUP. Artinya akan tambahan royalti yang dibayarkan ke pemerintah dari kedua IUP ini. Penambangan perbatasan IUP sudah diatur dalam Kepmen ESDM No. 1827K/30/MEM/2018 Pada Lampiran II Mengenai Pedoman Pengelolaan Teknis Pertambangan
\end{abstract}

Kata Kunci: Sharing Wall Project, konservasi, cadangan marginal, royalti.

\begin{abstract}
One of conservation efforts for mineral and coal resources (as mandated in PP No. 55 of 2010) is the management and or utilization of marginal reserves. An example of utilizing this marginal reserve is by maximizing the mining of coal reserves at the boundary between 2 (two) or several conflicting concessions. Coal reserves at this border are often left behind due to several considerations from concession holders. This paper uses a case study on joint mining in the PT Banjarsari Pribumi (PTBP) and PT Budi Gema Gempita (PTBGG) in Lahat Regency, South Sumatra. Mining cooperation at the intersection of concessions that coincide with each other is called the "Sharing Wall Project". The purpose of writing this paper is to provide information and guidance to concession holders who coincide with each other in conducting mining cooperation in accordance with applicable laws and regulations. Until now the "Sharing Wall Project" between PTBP and PTBGG has mined 350,000 tons of coal from the Sharing Wall Project for each concession. With this "Sharing Wall Project" it has the potential to increase marginal reserves of 1,000,000 tons that can be mined for each concession. This means that additional royalties will be paid to the government from these two concessions. Concessions border mining has been regulated in ESDM Decree No. 1827K / 30 / MEM / 2018 in Appendix II Concerning Guidelines for Mining Technical Management
\end{abstract}

Keywords: Sharing Wall Project, conservation, marginal reserves, royalties. 


\section{A. PENDAHULUAN}

\section{A.1. Latar Belakang}

Idealnya batas sebuah konsesi pertambangan bersinggungan satu sama lain dengan pemegang konsesi yang ada disekitarnya. Akan tetapi ada beberapa kasus ditemukan keadaan dimana antara sebuah konsesi tidak saling bersinggungan sehingga terdapat ruang (koridor) pemisah antara kedua atau beberapa konsesi yang bersebelahan tersebut. Koridor ini bisa jadi terbentuk akibat adanya misalnya ijin usaha yang dikeluarkan oleh instansi yang berbeda dan harus dipisahkan untuk mencegah adanya tumpang tindih perijinan. Kemungkinan yang lain adalah adanya kawasan tertentu yang tidak boleh dimasukkan ke dalam konsesi pertambangan seperti kawasan hutan lindung. Dengan pertimbangan tertentu pemerintah pastinya sudah mempertimbangkan hal tersebut pada saat proses pemberian ijin sebuah konsesi pertambangan.

Pada tahun 2015 Pulau Kalimantan memegang kepemilikan Izin Usaha Pertambangan (IUP) batu bara terbanyak di Indonesia mencapai 2.700 IUP. Pulau Sumatra ada di urutan kedua dengan 991 IUP dan Papua urutan ketiga mencapai 119 IUP. Empat tahun kemudian, tahun 2019, total IUP dan Izin Pertambangan Rakyat (IPR) berjumlah 3.161 IUP di seluruh Indonesian yang terdiri 2.061 IUP Mineral Logam dan Batubara, 543 IUP Mineral Non Logam dan Batubara serta 16 IPR. Sebagian besar IUP tersebut bersinggungan satu sama lainnya. Jika IUP-IUP yang saling bersinggungan ini tidak melakukan kerjasama penambangan pada area perbatasan maka dipastikan akan menimbulkan masalah tidak optimalnya usaha konservasi. Salah satu masalah konservasi tersebut adalah tidak optimalnya atau berkurangnya cadangan tertambang pada area perbatasan IUP. Tidak optimalnya penambangan di area ini akan berdampak pada jumlah PNBP (royalty) dan pajak yang akan diterima oleh negara.

Dalam Undang Undang No 4 Tahun 2009 tentang Pertambangan Mineral dan Batubara dituliskan bahwa salah satu kewajiban pemegang IUP adalah melakukan konservasi. Salah satu bentuk usaha konservasi ini dijelaskan dalam Kepmen ESDM No. 1827K/30/MEM/2018 Pada Lampiran II Mengenai Pedoman Pengelolaan Teknis Pertambangan adalah penambangan di perbatasan IUP.

Konservasi adalah upaya pengelolaan dan pemanfaatan mineral dan batubara secara bijaksana dan bertanggungjawab untuk dapat digunakan secara optimal pada saat ini dan masa yang akan datang. Ada beberapa alasan kenapa tidak dilakukannya kerjasama penambangan di perbatasan ini oleh beberapa pemegang IUP diantaranya:

1. Waktu penambangan yang tidak bersamaan.

2. Sequence penambangan yang tidak bersamaan.

3. Parameter geometri pit yang tidak identik.

4. Kebijakan dan komitmen antara pemegang IUP.

5. Isu-isu lain misalnya isu sosial, pembebasan lahan dan lain sebagainya.

Idealnya cadangan batubara yang ada diperbatasan antara dua atau beberapa IUP ini tambang dengan melakukan kerjasama operasional penambangan antara beberapa IUP tersebut. Kerjasama operasional penambangan di perbatasan dua atau beberapa IUP ini dinamakan Sharing Wall Project.

\section{A.2. Tujuan}

Makalah ini dibuat untuk memberikan panduan kepada para pemegang konsesi/IUP dalam melakukan kerjasama operasional penambangan di area perbatasan IUP. Kajiannya dibuat berdasarkan beberapa aspek seperti aspek hukum, aspek teknis, aspek ekonomi dan aspek keselamatan pertambangan dan perlindungan lingkungan. Makalah ini juga mencoba menjelaskan kepada semua stake holder bahwa penambangan bersama di perbatasan IUP memberikan dampak yang besar terhadap jumlah besaran cadangan yang bisa ditambang, tambahan royalti dan pajak yang akan diterima oleh pemerintah. 


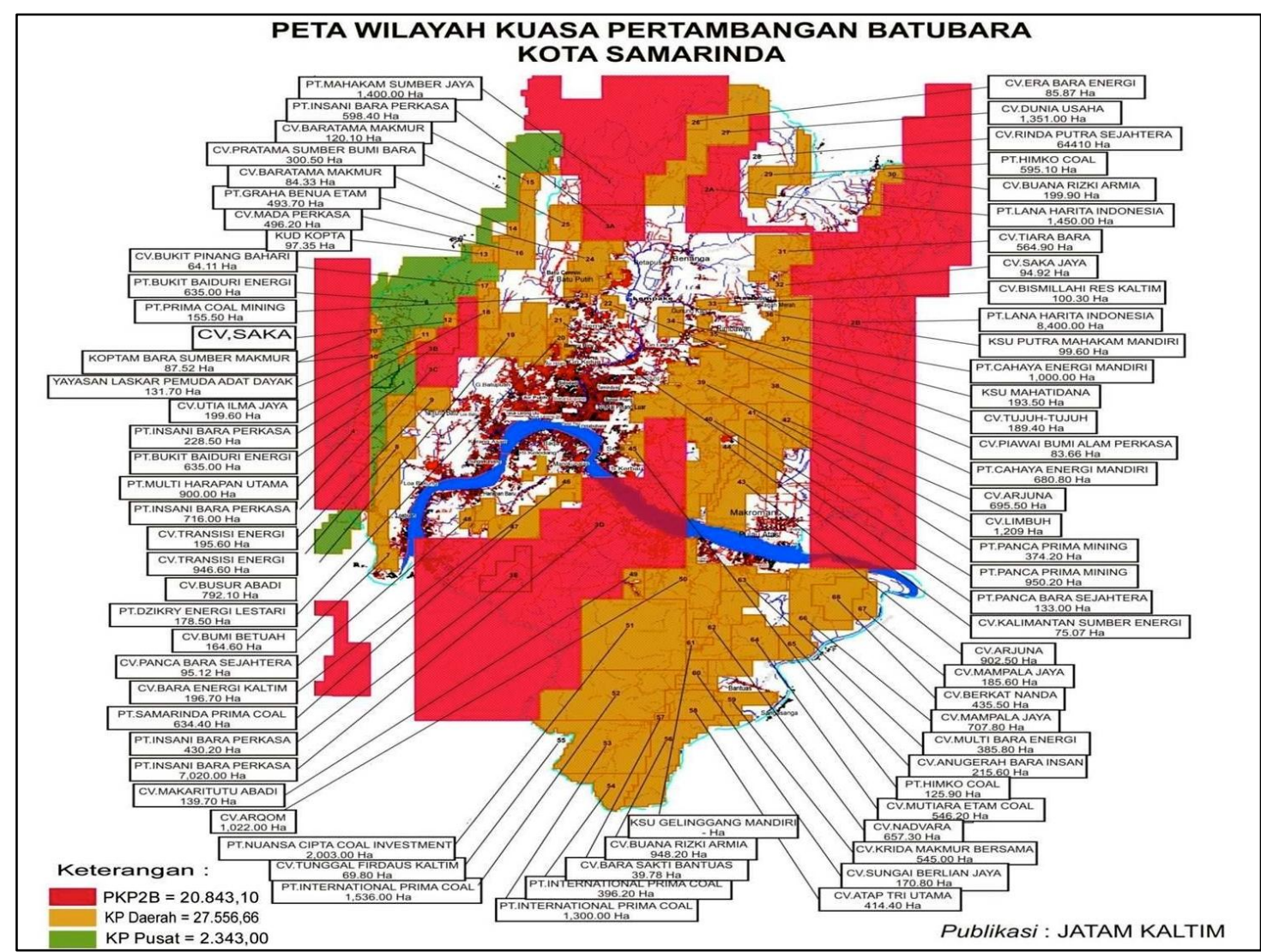

Gambar 1. Peta Wilayah Konsesi Pertambangan Batubara di sekitar Kota Samarinda

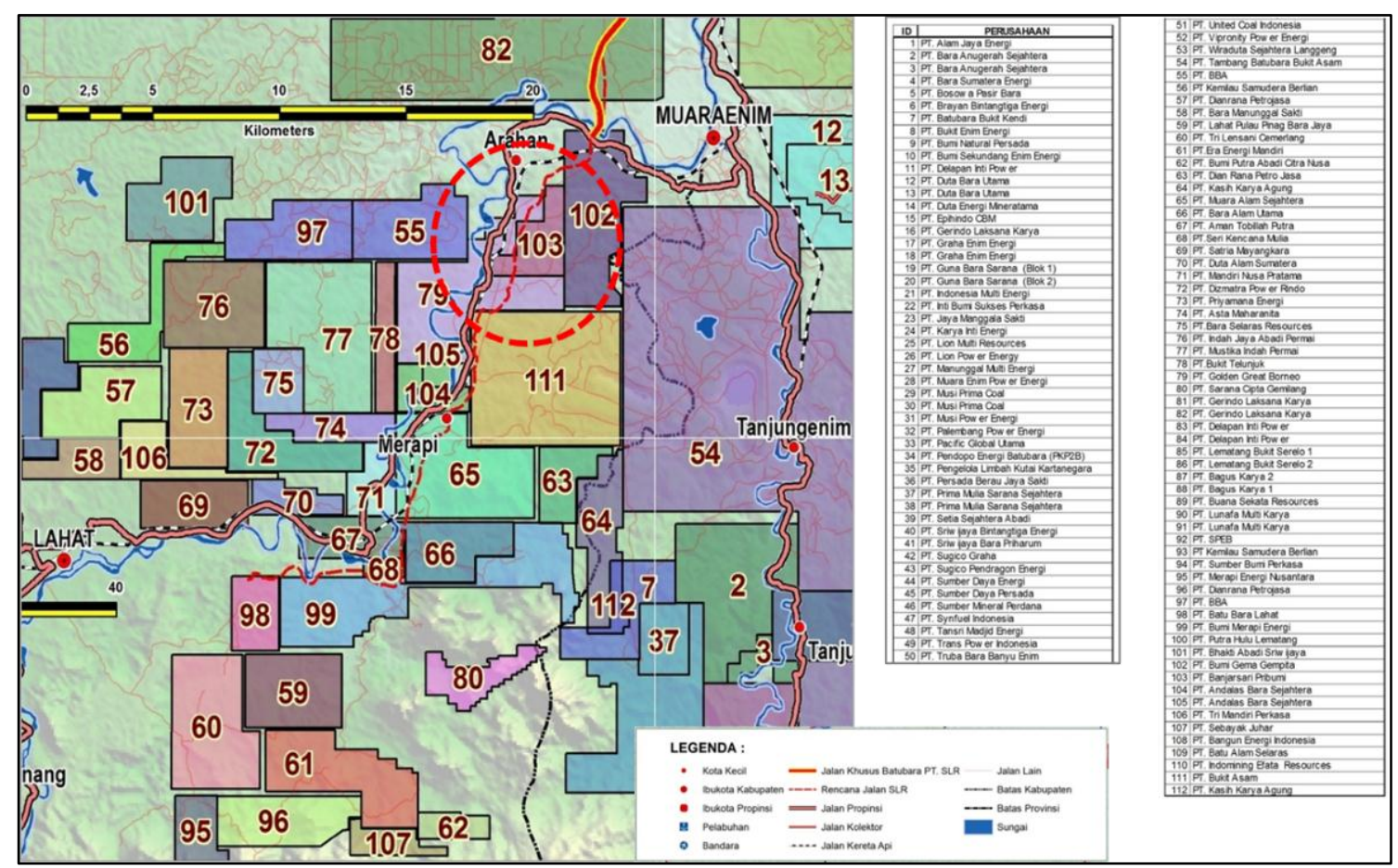

Gambar 2. Peta Wilayah Konsesi Pertambangan Batubara di sekitar Kabupaten Lahat dan Muara Enim 


\section{A. 3 Studi Kasus}

Studi kasus yang digunakan pada makalah ini adalah Sharing Wall Project antara IUP PT. Banjarsari Pribumi dan PT. Budi Gema Gempita di Kecamatan Merapi Timur, Kabupatan Lahat, Sumatera Selatan.

Inisiasi kerjasama ini dimulai pada tahun 2016 dan baru terealisasi tahun berikunya dan merupakan yang pertama kali dilakukan di Sumatera Selatan. Kasus kerjasama kali ini cukup menarik karena proses legal dan kerjasama itu sendiri dilakukan disaat belum keluarnya Kepmen ESDM No. 1827K/30/MEM/2018 yang secara jelas menyantumkan mengenai kerjasama di perbatasan IUP.

Rangkaian proses pengurusan Sharing Wall Project dikala itu adalah sebagai berikut:

1. Tanggal 14 Maret 2016 : Pertemuan Membahas Rencana Kerjasama Penambangan di Perbatasan BP-BGG

2. Tanggal 1 November 2016 : Penandatangan MoU BP-BGG

3. Tanggal 29 Desember 2016 : Rapat Membahas Teknis Kerja Sama Wall Sharing BP-BGG

4. Tanggal 3 Januari 2017 : Pemberitahuan Resmi ke Dinas Pertambangan dan Energi Provinsi Sumatera Selatan Perihal Perjanjian Kerjasama Penambangan dan Penimbunan Bersama Di Perbatasan PT. BP dan PT. BGG.

5. Tanggal 23 Januari 2017: Pemaparan Kerjasama Penambangan dan Penimbunan Bersama Di Perbatasan PT. BP dan PT. BGG di Dinas Pertambangan dan Energi Provinsi Sumatera Selatan Dan penandatanganan Kerjasama.

6. Tanggal 19 Juli 2017: Survey lokasi kerjasama penambangan PTBP dan PTBGG oleh Dinas Energi Sumberdaya Mineral Energi Provinsi Sumatera Selatan.

7. Tanggal 21 Juli 2017: Persetujuan kerjasama penambangan PTBP dan PTBGG disetuji oleh Kepala Dinas Energi Sumberdaya Mineral Energi Provinsi Sumatera Selatan.

8. Tanggal September 2017 : Kegiatan operasional penambangan di daerah perbatasan dimulai.

\section{B. PEMBAHASAN}

Sebelum melakukan perencanaan kerjasama penambangan di perbatasan perlu dilakukan beberapa hal untuk memastikan aktivitas ini layak untuk dilakukan, yaitu:

1. Membuat kesepakatan awal (MoU) dengan konsesi-konsesi terkait rencana kerjasama penambangan bersama di perbatasan.

2. Memastikan area rencana penambangan di perbatasan ini sudah tercantum/terencana dalam studi kelayakan yang ada. Jika belum, maka perlu dilakukan addendum dokumen studi kelayakan. Ada baiknya berkoordinasi terlebih dahulu dengan pihak terkait sebelum melakukan addendum dokumen ini.

3. Jika harus melakukan addendum dokumen studi kelayakan maka pastikan untuk melakukan addendum dokumen turunannya seperti dokumen AMDAL.

4. Berkoordinasi dengan pihak terkait

5. Membuat kesepakatan lebih lanjut antara pemegang IUP terkait aspek komersial, teknis pelaksanaan dan lain sebagainya.

Dalam pembahasan kerjasama penambangan di perbatasan IUP ini akan dikaji sesuai aspek-aspek yang terlingkup dalam dokumen studi kelayakan, yakni aspek teknis, aspek ekonomis dan lingkungan. Aspek hukum dan aspek keselamatan pertambangan juga dimasukkan dalam pembahasan.

\section{B. 1 Aspek Hukum}

Diatas telah dijelaskan bahwa kegiatan penambangan di perbatasan IUP merupakan salah satu bentuk upaya konservasi sumberdaya batubara. Dalam sistem perundang-undangan kita telah 
mengatur mengenai konservasi ini dimulai dari undang-undang sampai dengan turunannya. Landasan hukum Sharing Wall Project dapat dijelaskan sebagai berikut:

\section{Undang-Undang No.4 Tahun 2009 tentang Pertambangan Mineral dan Batubara:}

- Pasal 6 ayat (1) huruf k : Kewenangan Pemerintah dalam pengelolaan pertambangan mineral dan batubara, antara lain: penetapan kebijakan produksi, pemasaran, pemanfaatan, dan konservasi

- Pasal 39 ayat (2) huruf s, Pasal 79 huruf s mengenai kewajiban pemegang IUP terhadap konservasi mineral dan batubara

- Pasal 96 huruf d mengenai kewajiban pemegang IUP untuk melaksanakan upaya konservasi sumber daya mineral dan batubara.

- Pasal 141 ayat (1) huruf e : pengawasan penyelenggaraan pengelolaan usaha pertambangan, antara lain, berupa konservasi sumber daya mineral dan batubara

\section{Peraturan Pemerintah No. 23 Tahun 2010 Tentang Pelaksanaan Kegiatan Usaha Pertambangan:}

- Pasal 89 ayat (2) yang menyatakan bahwa Menteri melakukan pengendalian produksi mineral dan batubara yang dilakukan oleh pemegang IUP Operasi Produksi mineral atau batubara dan IUPK Operasi Produksi mineral atau batubara yang salah satunya adalah mengenai pelaksanaan konservasi sumber daya mineral dan batubara;

Peraturan Pemerintah No. 55 Tahun 2010 Tentang Pembinaan dan Pengawasan Penyelenggaraan Pengelolaan Usaha Pertambangan Mineral dan Batubara:

- Pasal 16 huruf e: Pengawasan atas pelaksanaan usaha pertambangan dilakukan terhadap konservasi sumber daya mineral dan batubara.

- Pasal 25 ayat (1): Pengawasan konservasi sumber daya mineral dan batubara sebagaimana dimaksud dalam Pasal 16 huruf e paling sedikit meliputi: recovery penambangan dan pengolahan; pengelolaan dan/ atau pemanfaatan cadangan marginal; pengelolaan dan/atau pemanfaatan batubara kualitas rendah dan mineral kadar rendah; pengelolaan dan/atau pemanfaatan mineral ikutan; pendataan sumber daya serta cadangan mineral dan batubara yang tidak tertambang; dan pendataan dan pengelolaan sisa hasil pengolahan dan pemurnian.

Peraturan Pemerintah No. 78 Tahun 2010 Tentang Reklamasi dan Pasca Tambang, Pasal 4 mengenai Prinsip Konservasi Sumberdaya Mineral dan Batubara, meliputi:

- Penambangan yang optimum.

- Penggunaan metode dan teknologi pengolahan dan pemurnian yang efektif dan efisien.

- Pengelolaan dan/atau pemanfaatan cadangan marginal, mineral berkadar rendah, mineral ikutan serta batubara berkadar rendah.

- Pendataan sumber daya serta cadangan mineral batubara yang tidak tertambang serta sisa pengolahan dan pemurnian.

Peraturan Menteri ESDM No. 26 Tahun 2018 tentang Pelaksanaan Kaidah Pertambangan Yang Baik dan Pengawasan Pertambangan Mineral dan Batubara, pasal 24 mengenai Konservasi Mineral dan Batubara, meliputi:

- Ayat (1) Pemegang IUP Eksplorasi, IUPK Eksplorasi, IUP Operasi Produksi dan IUPK Operasi Produksi wajib melakukan upaya konservasi Mineral dan Batubara sebagaimana dimaksud dalam Pasal 3 ayat (3) huruf b.

- Ayat (2) Upaya konservasi Mineral dan Batubara sebagaimana dimaksud pada ayat (1) terdiri atas: a. perencanaan dan pelaksanaan recovery Penambangan; b. perencanaan dan pelaksanaan recovery pengolahan; c. pengelolaan Batubara kualitas rendah dan Mineral kadar rendah, Mineral ikutan, sisa hasil Pengolahan dan/atau Pemurnian, dan cadangan marginal; d. pemanfaatan Batubara kualitas rendah dan Mineral kadar rendah, Mineral 
ikutan, dan cadangan marginal; dan e. pendataan cadangan Mineral dan Batubara yang tidak tertambang dan sisa hasil Pengolahan dan/atau Pemurnian.

\section{Peraturan Menteri ESDM No. 7 Tahun 2014 tentang Pelaksanaan Reklamasi dan Pascatambang Pada Kegiatan Usaha Pertambangan Mineral dan Batubara, pasal 2 mengenai Prinsip Konservasi Sumberdaya Mineral dan Batubara, meliputi: \\ - Penambangan yang optimum \\ - Penggunaan metode dan teknologi pengolahan dan pemurnian yang efektif dan efisien \\ - Pengelolaan dan/atau pemanfaatan cadangan marginal, mineral berkadar rendah, mineral ikutan serta batubara berkadar rendah \\ - Pendataan sumber daya serta cadangan mineral batubara yang tidak tertambang serta sisa pengolahan dan pemurnian.}

\section{Keputusan Menteri ESDM No. 1827K/30/MEM/2018 tentang Pedoman Pelaksanaan Kaidah Teknik Pertambangan yang Baik, Lampiran II Mengenai Pedoman Pengelolaan Teknis Pertambangan, xii. Penambangan Bersama Perbatasan WIUP:}

i. dalam hal dilakukan penambangan bersama antar pemegang IUP Operasi Produksi untuk keberlanjutan umur tambang maka wajib mematuhi ketentuan peraturan perundangundangan dan memenuhi persyaratan: (a) berbatasan langsung dan tidak dipisahkan koridor; (b) sudah dilakukan pemasangan tanda batas pada masing-masing WIUP yang akan melakukan penambangan bersama; (c) jumlah estimasi sumber daya paling kurang klasifikasi terunjuk; dan

(d) memiliki kajian teknis penambangan;

ii. kajian teknis tersebut paling kurang mencakup: (a) jumlah sumber daya yang dapat dikonversi menjadi cadangan pada masing-masing wilayah; (b) perencanaan penambangan bersama

sesuai dengan rencana penambangan yang dituangkan dalam dokumen RKAB Tahunan yang telah disetujui; dan (c) analisis risiko;

iii. perjanjian kerja sama antar pemegang IUP yang paling sedikit terdiri atas; (a) administrasi meliputi lokasi, jangka waktu, volume, dan pelaksana; (b) pengaturan operasional penambangan berdasarkan kesepakatan antara Kepala Teknik Tambang meliputi aspek penambangan, aspek keselamatan pertambangan, dan aspek perlindungan lingkungan; (c) klausul tertentu terkait risiko keberlanjutan proyek, perselisihan, dan kondisi kahar;

iv. hasil kajian teknis tersebut disampaikan dalam laporan khusus kepada Kepala Inspektur Tambang;

Dapat dilihat bahwa sebelum di-undangkannya Keputusan Menteri ESDM No. 1827K/30/MEM/2018 diatas tidak ada satupun dari peraturan perundangan-undangan yang secara tersurat mencantumkan dan mengatur secara spesifik mengenai kerjasama di perbatasan IUP. Kondisi ini bisa saja menimbulkan perbedaan persepi dari kalangan pengusaha pemegang IUP maupun pemerintah terkait keabsahan kegiatan kerjasama ini, seperti apa prosesnya administrasinya dan lain sebagainya. Hal ini pun sempat dialami PTBP dan PTBGG saat waktu memulai pengurusan kerjasama ini. Pada saat itu pihak terkait sempat ada yang pesimis terkait kerjasama ini karena tidak ada peraturan yang secara spesifik atau tersurat menjelaskan kerjasama di perbatasan sehingga justru dikuatirkan dapat menimbulkan masalah atau perselisihan. Setelah dilakukan pembahasan dengan melibatkan semua pihak terkait barulah kerjasama ini bisa berjalan.

Saat ini, untuk pemegang IUP yang berencana melakukan kerjasama penambangan di perbatasan sudah diatur dalam Keputusan Menteri ESDM No. 1827K/30/MEM/2018 diatas.

\section{B. 2 Aspek Teknis}

Batas IUP PTBP sebelah timur bersinggungan dengan batas bagian barat IUP PTBGG (dapat dilihat pada Gambar 2). Sementara itu batas IUP PTBP bagian barat dan selatan bersebelahan dengan IUP PT Golden Great Borneo (PTGGB), kedua IUP ini tidak saling bersinggungan. 
Dengan kata lain terdapat area/koridor pemisah antara IUP PTBP dan PTGGB. Koridor ini statusnya merupakan bukan konsesi yang dimiliki oleh perusahaan atau instansi manapun sehingga sering disebut sebagai area tidak bertuan. Koridor ini memisahkan IUP PTBP dan PTGGB sejauh 40-50 meter satu sama lainnya. Secara aturan koridor pemisah ini tidak boleh diganggu atau ditambang meskipun hanya dibatasi oleh beberapa meter saja. Setiap kegiatan yang dilakukan pertambangan/penambangan yang dilakukan di luar IUP tanpa ada izin dari pihak terkait dikategorikan sebagai tindakan pidana dengan ancaman hukuman 10 (sepuluh) tahun penjara.

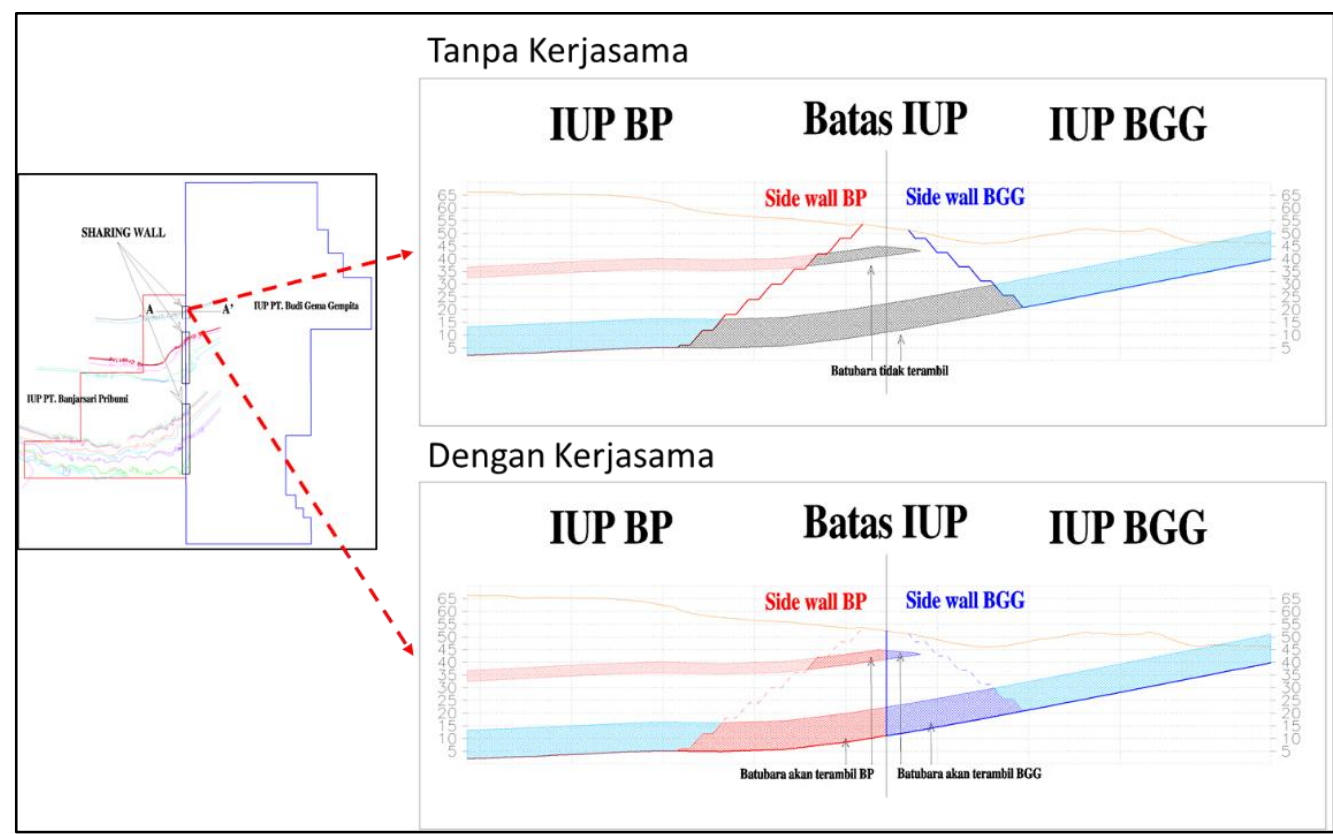

Gambar 3. Lingkup Kerjasama Penambangan Batubara di perbatasan IUP PTBP dan PTBGG

Beberapa pertimbangan teknis agar Sharing Wall Project ini dapat berjalan dengan semestinya, yaitu:

1. Garis batas masing-masing IUP bersinggungan.

Kerjasama Sharing Wall ini hanya akan bisa dilakukan jika garis batas masing-masing IUP bersinggungan. Jika terdapat celah (koridor) maka kerjasama ini tidak bisa dilakukan.

2. Masing-masing IUP membuka pit di kawasan yang sama.

Kerjasama Sharing Wall tidak bisa berjalan lancar jika masing-masing IUP tidak membuka pit di kawasan yang sama karena penurunan pit di perbatasan harus dilakukan secara bersama-sama.

3. Parameter design kedua IUP harus identik.

Parameter design (tinggi bench, lebar bench dan sebagainya) dan SR (Striping Ratio) kedua IUP harus identik sehingga harapannya pertemuan kedua pit (tambang) nanti tidak compang akibat dimensi yang berbeda.

4. Harus adanya kesamaan komitmen dalam pengelolaan air tambang.

Dalam prakteknya dengan dibuka area perbatasan maka hal lain yang seringkali muncul adalah masuknya air permukaan/limpasan dari IUP yang satu ke IUP yang lain. Sehingga perlu dibuat perencanaan air permukaan (Water Management System) yang disepakati oleh para pihak.

5. Optimalisasi dalam penutupan lubang bekas tambang

Penutupan lubang bekas tambang merupakan bagian penting dalam rangkaian kegiatan penambangan. Lubang bekas tambang akibat penggalian di perbatasan ini juga perlu 
disepakati oleh para pemegang IUP untuk segera dilakukan penutupan kembali agar tidak ada masalah lain muncul seperti masalah lingkungan dan kestablilan lereng.

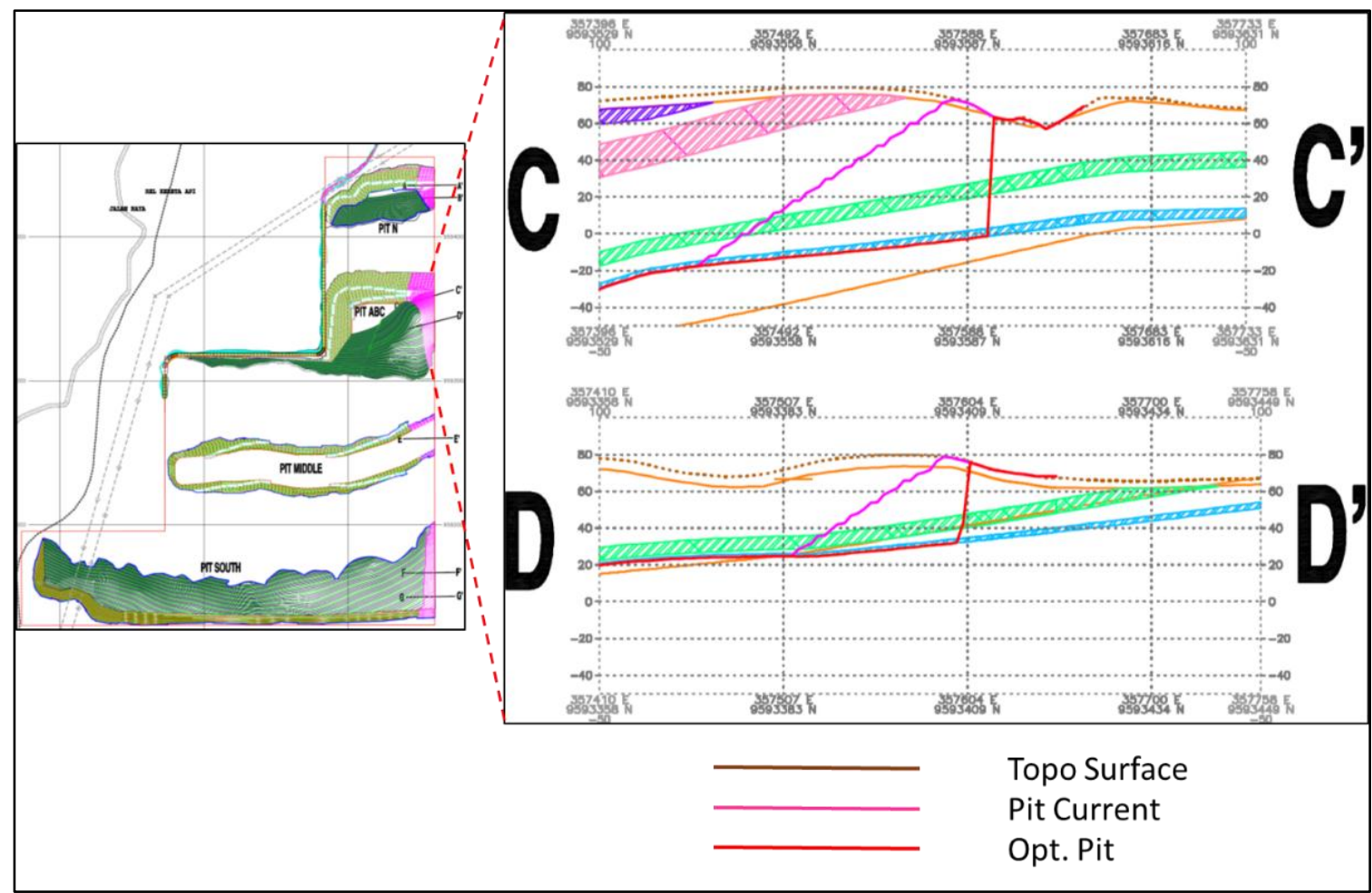

Gambar 4. Lingkup Kerjasama Penambangan Batubara di perbatasan IUP PTBP dan PTBGG

\section{B. 3 Aspek Ekonomi}

Ditinjau dari segi ekonomi, ada beberapa benefit yang bisa didapatkan dari Sharing Wall Project ini diantaranya menambah sumberdaya/cadangan tertambang (reserve), mengoptimalisasi biaya pembebasan lahan terhadap kuantitas batubara yang ditambang, menambah kapasitas volume disposal dan menambah pendapatan pemerintah dari royalti. Sampai saat ini Sharing Wall Project antara IUP PTBP dan PTBGG ini sudah menambang batubara sebesar 350,000 ton dari Sharing Wall Project ini untuk masing-masing konsesi. Potensi tambahan cadangan yang tertambang secara keseluruhan dari Sharing Wall Project ini dapat dilihat pada Tabel 1.

\section{B. 4 Aspek Keselamatan Pertambangan dan Perlindungan Lingkungan}

Beberapa pertimbangan yang harus dilakukan dalam melakukan kerjasama penambangan ini ditinjau dari aspek keselamatan pertambangan dan perlindungan lingkungan, seperti:

1. Untuk memudahkan dalam proses penambangannya maka sangat disarankan untuk menunjuk salah satu pihak (kontraktor) dalam melakukan kegiatan penambangan. Hal ini untuk memudahkan kedua belah pihak dalam berkomunikasi selama proses penambangan. Bisa dibayangkan jika daerah perbatasan ini dilakukan oleh masing-masing maka akan dapat memicu kecelakaan tambang misalnya karena masing-masing kontraktor menggunakan channel radio yang berbeda, menggunakan SOP yang berbeda, dimensi alat yang berbeda dan lain sebagainya.

2. Perlu dibuat SOP khusus kerjasama di area perbatasan ini yang disepakati oleh masingmasing Kepala Teknik Tambang (KTT).

3. Ada komitmen bersama dalam pengelolaan air tambang dan penutupan dan reklamasi lubang bekas tambang sesuai dengan dokumen yang ada (AMDAL, Rencana Reklamasi dan Rencana Penutupan Tambang). 
Tabel 1. Hasil perhitungan cadangan batubara di perbatasan IUP PTBP dan PTBGG

\begin{tabular}{|c|c|c|c|c|c|c|c|c|c|c|c|c|c|c|}
\hline \multicolumn{15}{|c|}{ PIT ABC } \\
\hline Row Label & $\begin{array}{l}\text { Sum of TOTAL } \\
\text { VOLUME (OB) }\end{array}$ & $\begin{array}{c}\text { Sum of MASS } \\
\text { (Coal) }\end{array}$ & TRUEVER & ASH & CVAD & CVAR & FC & HGI & ID & IM & RD & TM & TS & VM \\
\hline A1 & 877.13 & $1,221.46$ & 0.70 & 2.62 & $5,823.00$ & $4,714.00$ & 41.02 & - & 1.26 & 14.18 & - & 30.52 & 2.36 & 42.18 \\
\hline $\mathrm{A} 2$ & 925.39 & $5,402.99$ & 2.98 & 2.62 & \begin{tabular}{|l|}
$5,823.00$ \\
\end{tabular} & $4,714.00$ & 41.02 & - & 1.26 & 14.18 & - & 30.52 & 2.36 & 42.18 \\
\hline A3 & 160.26 & 988.77 & 0.52 & 2.76 & $5,988.00$ & $4,497.00$ & 42.56 & - & 1.26 & 11.79 & - & 33.75 & 0.83 & 42.89 \\
\hline A4 & 103.80 & 708.59 & 0.38 & 2.76 & $5,988.00$ & $4,497.00$ & 42.56 & - & 1.26 & 11.79 & - & 33.75 & 0.83 & 42.89 \\
\hline A5 & 288.85 & $2,145.40$ & 1.13 & 2.76 & \begin{tabular}{|l|}
$5,988.00$ \\
\end{tabular} & $4,497.00$ & 42.56 & - & 1.26 & 11.79 & - & 33.75 & 0.83 & 42.89 \\
\hline A6 & 204.50 & $1,295.17$ & 0.67 & 2.72 & \begin{tabular}{|l|}
$5,874.00$ \\
\end{tabular} & $4,502.00$ & 41.64 & - & 1.26 & 13.13 & - & 33.42 & 0.29 & 42.61 \\
\hline $\mathrm{AL}$ & $6,046.96$ & $43,388.94$ & 17.48 & 3.62 & \begin{tabular}{|l|}
$5,784.05$ \\
\end{tabular} & $4,530.81$ & 40.96 & 62.61 & 1.19 & 13.91 & 1.22 & 32.44 & 0.32 & 41.70 \\
\hline$B$ & $40,454.98$ & $99,301.84$ & 19.29 & 8.19 & \begin{tabular}{|l|}
$5,613.36$ \\
\end{tabular} & $4,449.94$ & 38.78 & 62.79 & 1.27 & 12.34 & 1.30 & 30.35 & 0.27 & 40.70 \\
\hline C & $629,701.91$ & $232,020.32$ & 7.30 & 5.68 & \begin{tabular}{|l|}
$5,733.85$ \\
\end{tabular} & $4,750.09$ & 39.80 & 60.56 & 1.25 & 15.00 & 1.29 & 29.56 & 0.57 & 39.50 \\
\hline D & $260,110.50$ & $78,426.06$ & 2.15 & 8.41 & $5,555.11$ & $4,537.32$ & 39.13 & 63.00 & 126.00 & 13.28 & 1.29 & 28.94 & 1.53 & 39.30 \\
\hline Total & $938,874.28$ & $464,899.53$ & & & & & & & & & & & & \\
\hline \multicolumn{15}{|c|}{ PIT N } \\
\hline Row Label & $\begin{array}{l}\text { Sum of TOTAL } \\
\text { VOLUME (OB) }\end{array}$ & $\begin{array}{c}\text { Sum of MASS } \\
\text { (Coal) }\end{array}$ & TRUEVER & ASH & CVAD & CVAR & FC & HGI & ID & IM & RD & TM & TS & VM \\
\hline N11 & $148,137.83$ & $99,525.34$ & 11.07 & 40.42 & $5,144.78$ & $3,692.11$ & 34.53 & 63.21 & 1.20 & 19.01 & 1.23 & 41.97 & 0.27 & 42.30 \\
\hline N12 & $62,674.61$ & $26,279.18$ & 3.69 & 7.19 & $4,774.81$ & $3,309.44$ & 33.31 & 64.13 & 1.24 & 18.91 & 1.28 & 43.78 & 0.26 & 40.50 \\
\hline N15 & $160,836.53$ & $18,767.65$ & 10.23 & 9.41 & \begin{tabular}{|l|}
$4,867.55$ \\
\end{tabular} & $3,336.90$ & 30.98 & 64.79 & 1.24 & $\begin{array}{l}18.31 \\
\end{array}$ & 1.28 & 43.62 & 0.26 & 41.30 \\
\hline Total & $371,648.97$ & $144,572.17$ & & & & & & & & & & & & \\
\hline \multicolumn{15}{|c|}{ PIT South } \\
\hline Row Label & $\begin{array}{l}\text { Sum of TOTAL } \\
\text { VOLUME (OB) }\end{array}$ & $\begin{array}{c}\text { Sum of MASS } \\
\text { (Coal) }\end{array}$ & TRUEVER & ASH & CVAD & CVAR & FC & HGI & ID & IM & RD & TM & TS & VM \\
\hline SK L & $1,203.29$ & $5,077.95$ & 1.16 & 18.90 & $4,189.78$ & $3,049.99$ & 28.53 & 60.98 & 1.35 & 16.75 & 1.58 & 39.39 & 0.27 & 35.82 \\
\hline SKU & $6,692.77$ & $5,644.97$ & 1.84 & 22.08 & $4,268.51$ & $3,153.69$ & 26.91 & 67.00 & 1.33 & 13.49 & 1.52 & 36.01 & 0.25 & 37.57 \\
\hline SM & $1,449.67$ & $4,467.98$ & 10.67 & 5.03 & \begin{tabular}{|l|}
$5,266.64$ \\
\end{tabular} & $3,773.28$ & 35.62 & 62.85 & 1.28 & 16.97 & 1.28 & 40.52 & 0.28 & 42.38 \\
\hline SML & $37,513.18$ & $235,639.99$ & 6.43 & - & - & - & - & - & 1.29 & - & - & - & - & - \\
\hline SMLL & $11,384.44$ & 28.97 & 3.93 & - & - & - & - & - & 1.29 & - & - & - & - & - \\
\hline SMU & $395,797.91$ & $150,490.63$ & 4.72 & - & - & - & - & - & 1.29 & - & - & - & - & - \\
\hline Total & $454,041.26$ & $401,350.49$ & & & & & & & & & & & & \\
\hline \multicolumn{15}{|c|}{ PIT Middle } \\
\hline Row Label & $\begin{array}{l}\text { Sum of TOTAL } \\
\text { VOLUME (OB) }\end{array}$ & $\begin{array}{c}\text { Sum of MASS } \\
\text { (Coal) }\end{array}$ & TRUEVER & ASH & CVAD & CVAR & FC & HGI & ID & IM & RD & TM & TS & VM \\
\hline$A M$ & $14,039.20$ & $8,829.52$ & 29.79 & 3.62 & \begin{tabular}{|l|}
$5,784.05$ \\
\end{tabular} & $4,530.81$ & 40.96 & 62.61 & 1.19 & 13.91 & 1.22 & 32.44 & 0.32 & 41.70 \\
\hline BM & $7,525.69$ & $6,889.00$ & 32.33 & 8.19 & \begin{tabular}{|l|}
$5,613.36$ \\
\end{tabular} & $4,449.94$ & 38.78 & 62.79 & 1.27 & 12.34 & 1.30 & 30.35 & 0.27 & 40.70 \\
\hline $\mathrm{CM}$ & $22,346.35$ & $3,555.54$ & 44.27 & 5.68 & $5,733.85$ & $4,750.09$ & 39.80 & 60.56 & 1.25 & 15.00 & 1.29 & 29.56 & 0.57 & 39.50 \\
\hline Total & $43,911.24$ & $19,274.06$ & & & & & & & & & & & & \\
\hline
\end{tabular}

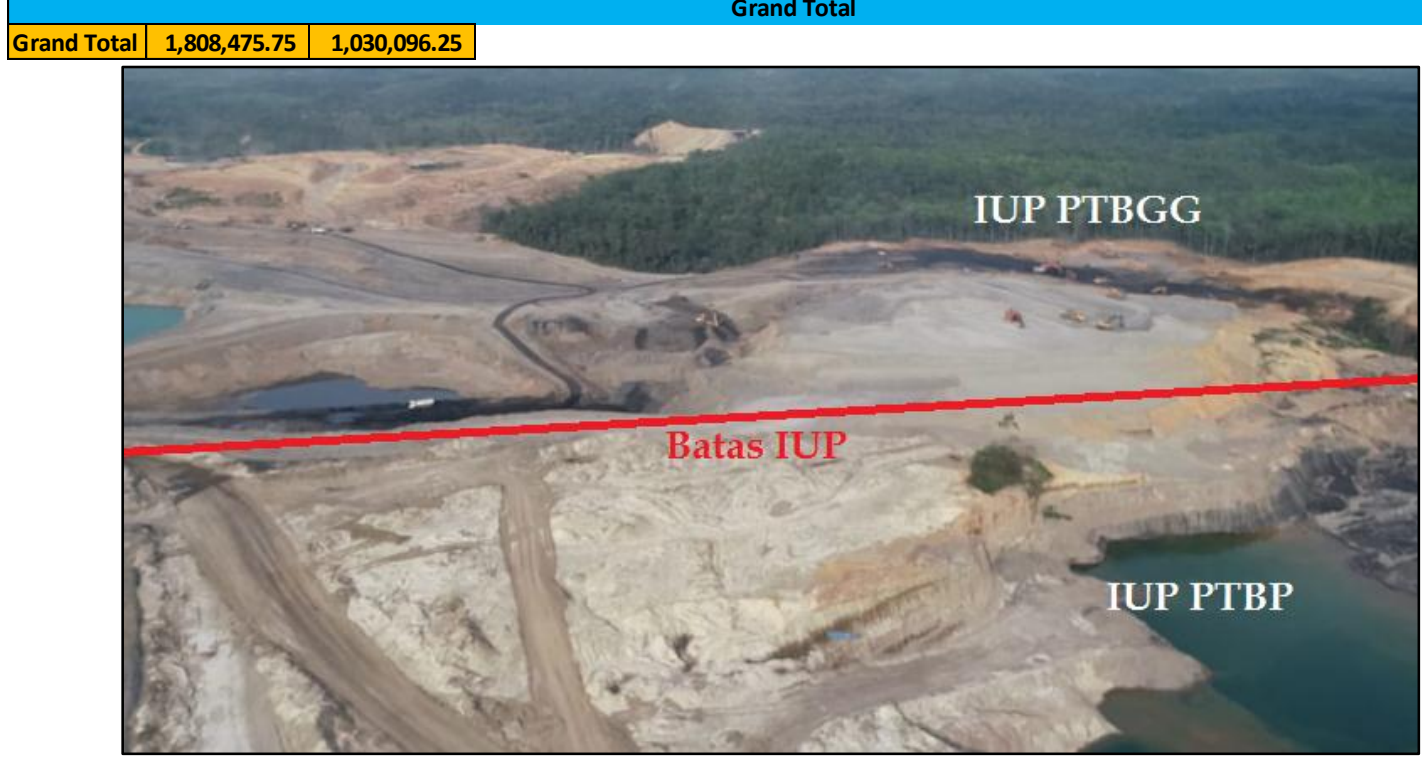

Gambar 5. Aktivitas penambangan Sharing Wall Project (bulan September 2018) 


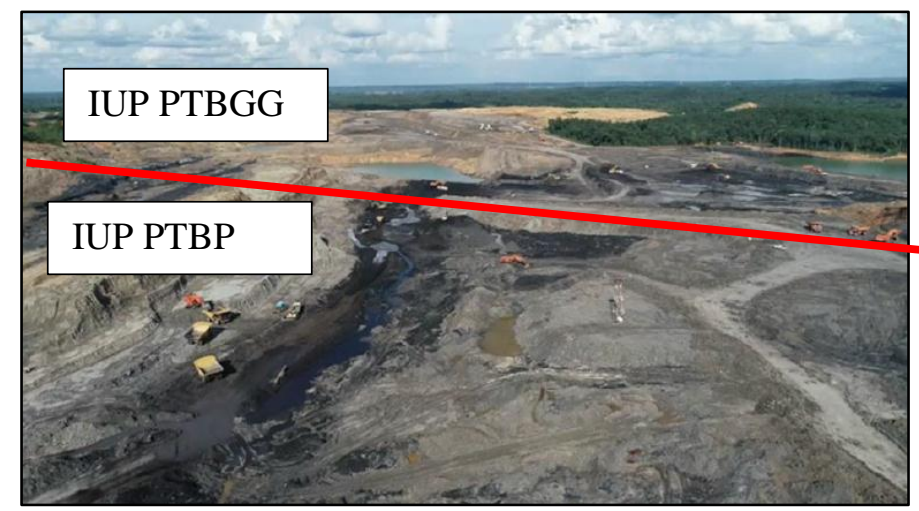

Gambar 6. Aktivitas penambangan Sharing Wall Project (bulan April 2019)

\section{KESIMPULAN}

Ditinjau dari aspek hukum, kerjasama Sharing Wall Project sudah diatur dalam sistem perundangundangan sehingga bisa dilakukan oleh pemegang IUP yang bersinggungan. Dari segi ekonomis hal ini bisa menambah sumberdaya/cadangan tertambang (reserve), mengoptimalisasi biaya pembebasan lahan terhadap kuantitas batubara yang ditambang, menambah kapasitas volume disposal dan menambah pendapatan pemerintah dari royalti. Agar kerjasama ini berjalan dengan baik maka pemegang IUP yang terkait perlu melakukan beberapa hal agar aspek keselamatan pertambangan dan perlindungan lingkungan sesuai dengan regulasi yang ada.

\section{UCAPAN TERIMA KASIH}

Pada kesempatan ini penulis ucapkan terima kasih yang sebesar-besarnya atas pihak-pihak yang telah mensukseskan kerjasama Sharing Wall Project ini sehingga semua nya dapat tertuang dalam sebuah makalah yang dapat dijadikan panduan oleh para pemegang IUP. Terima kasih tersebut kami tujukan kepada:

1. Kepala Dinas Energi Sumberdaya Mineral Energi Provinsi Sumatera Selatan.

2. Staf Seksi Teknik dan Lingkungan Dinas Energi Sumberdaya Mineral Energi Provinsi Sumatera Selatan.

3. Staf Seksi Pembinaan dan Pengusahaan Dinas Energi Sumberdaya Mineral Energi Provinsi Sumatera Selatan.

4. Inspektur Tambang (Area Pengawasan Provinsi Sumatera Selatan)

5. Kepala Teknik Tambang dan Direksi PT. Budi Gema Gempita

6. Direksi dan Staf PT. Banjarsari Pribumi

\section{DAFTAR PUSAKA}

Dasar hukum perundangan-undangan, diperoleh melalui situs internet: https://jdih.esdm.go.id. Diunduh pada tanggal 30 Agustus 2019.

Data jumlah IUP tahun 2015 dan 2019, diperoleh melalui situs internet: https://www.minerba.esdm.go.id/show/show_pdf?link_file=104. Diunduh pada tanggal 7 September 2019.

Permana, Herry. (2017): Konservasi Mineral dan Batubara, Modul Pendidikan dan Pelatihan Pengawas Operasional Utama 2017, Direktorat Teknik dan Lingkungan Minerba Direktorat Jenderal Minerba, Bandung, 5, 9 - 23. 
Peta Wilayah Konsesi Pertambangan Batubara di sekitar Kota Samarinda diperoleh melalui situs internet: https://databoks.katadata.co.id/datapublish/2016/08/16/jumlah-kepemilikan-izinusaha-pertambangan-batubara-di-indonesia Diunduh pada tanggal 7 September 2019. 
PROSIDING TPT XXVIII PERHAPI 2019 